\title{
Pelatihan Penyusunan Rencana Anggaran Biaya Talud di Desa Tladan Kecamatan Kawedanan Kabupaten Magetan
}

\author{
Rosyid Kholilur Rohman ${ }^{1)}$, Setiyo Daru Cahyono ${ }^{2)}$, Seno Aji ${ }^{3)}$ \\ ${ }^{1,2,3)}$ Prodi Teknik Sipil, Fakultas Teknik, Universitas Merdeka Madiun, Jl. Serayu No.79, Kota Madiun, 63131 \\ E-mail: rosyid@unmer-madiun.ac.id, setivodaru@unmer-madiun.ac.id, senoaji@unmer-madiun.ac.id
}

\begin{abstract}
The government promotes rural infrastructure development through Village Fund Allocation (ADD). In the process of planning, development and reporting the village government is given the broadest authority. This authority requires the village government to have the ability to prepare a Budget Plan $(R A B)$ and report on the use of funds. The ability of village communities in preparing Budget Planfor the Talud is still minimal and training is needed to improve their abilities. The results of this training are expected to be beneficial for the people of Tladan Village, Kawedanan District, Magetan regency so that the infrastructure development program in the village will run better and achieved good quality.
\end{abstract}

Keywords-: infrastructure; Budget Plan; Talud.

\section{PENDAHULUAN}

Rencana Anggaran Biaya (RAB) berfungsi untuk menghitung biaya kebutuhan untuk menyelesaikan pekerjaan kontruksi. RAB disusun dengan memperhatikan beberapa aspek yaitu biaya bahan material yang dibutuhkan, upah tenaga kerja dan peralatan yang digunakan. RAB mempermudah pengambil kebijakan untuk memperkirakan jumlah anggaran yang dibutuhkan dalam pelaksaan konstruksi suatu bangunan. RAB juga digunakan sebagai pedoman dalam melaksanakan suatu pekerjaan dan pengontrol pelaksanaan pekerjaan.

Dalam penyusunan $\mathrm{RAB}$ proyek kontruksi diperlukan ketelitian dan bekal ilmu yang baik sehingga dapat dilaksanakan dengan baik sesuai anggaran yang ditetapkan. Seiring dengan kemajuan ilmu komputer dan tuntutan era modern, dibutuhkan alat bantu program komputer untuk menyusun RAB sehingga mempercepat proses penyusunannya.

Pemerintah tengah menggalakkan pembangunan infrastruktur pedesaan di berbagai wilayah Indonesia dengan menerapkan sistem swakelola masyarakat. Sistem swakelola ini diharapkan program pembangunan infrastruktur desa disusun berdasar aspirasi dan kebutuhan warga sehingga tepat sasaran dan dapat dirasakan manfaatnya oleh masyarakat. Sistem swakelola tersebut diharapkan dapat memaksimalkan penggunaan sumber daya yang ada dan memungkinkan masyarakat merencanakan sendiri program pembangunan infrastruktur desa sehingga sesuai dengan kebutuhan mereka.

Salah satu bangunan yang banyak dibangun di pedesaan adalah talud. Talud adalah dinding yang terbuat dari beton atau batu kali yang disusun sebagai struktur penahan tanah. Bangunan penahan tanah digunakan untuk menahan tekanan tanah lateral yang ditimbulkan oleh tanah urug atau tanah asli yang labil (Hardiyatmo, 2010). Sebagian besar dinding penahan tanah atau retaining wall ini dibuat dari pasangan batu kali yang diperkuat beton. Konstruksi ini berfungsi untuk menahan gaya tekanan aktif lateral suatu tanah maupun air, sehingga mampu memperbesar tingkat kestabilan tanah. Umumnya, talud penahan tanah ini dibuat pada daerah-daerah dengan kondisi tanah yang cenderung masih labil. 
Website : http://dayamas.unmermadiun.ac.id/index.php/dayamas

Talud juga dibutuhkan pada kostruksi bangunan, terutama gedung dan basement yang berada di atas kemiringan tertentu. Tujuan pembangunan talud tidak lain supaya tanah tersebut tahan terhadap guncangan dan tidak mudah goyah.

Pengetahuan masyarakat dalam penyusunan RAB khususnya talud, selama ini masih sangat terbatas dan sering menggunakan perhitungan manual. Oleh karea itu, perlu dilakukan pelatihan pembuatan $\mathrm{RAB}$ talud agar kemampuan dan keahlian masayarakat dalam pembuatan $\mathrm{RAB}$ dapat meningkat dan menghasilkan produk RAB Talud yang teliti dan akurat. Dengan pelatihan tersebut diharapkan dapat membantu kesulitan-kesulitan yang dihadapi dan memberikan solusi terbaik atas kendala-kendala tesebut. RAB Talud yang dibuat secara mandiri oleh masyarakat diharapkan dapat mengurangi tingkat ketergantungan pada pihak ketiga sehingga mengurangi biaya perencanaan serta dapat dilaksanakan sesuai sumber daya yang ada. Pengetahuan dalam penyusunan RAB talud juga diharapkan dapat digunakan sebagai dasar dalam penyusunan laporan pertanggungjawaban penggunaan dana pembangunan desa, khususnya pekerjaan dinding penahan tanah.

Adapun target dari kegiatan pelatihan ini adalah agar masyarakat memahami pengetahuan dasar konstruksi talud, beserta langkah dan cara penyusunan RAB talud. Selain itu, diharapkan masyarakat dapat menggunakan program komputer MS Excel dalam peyusunan rencana anggaran biaya sehingga mempermudah dan mempercepat pekerjaan.

Dampak sosial dari kegiatan ini adalah masyarakat dapat menyusun RAB talud, sehingga dapat mengurangi biaya perencanaan. Hal ini disebabkan, selama ini dalam penyusunan RAB talud selalu menggunakan jasa pihak ketiga. Dampak sosial lainnya adalah rencana pembangunan infrastruktur di desa akan dapat disusun oleh masyarakat secara mandiri serta dapat tepat sasaran sesuai kebutuhan mereka serta menyesuaikan sumber daya yang ada dan kualitas pekerjaan yang semakin baik sesuai spesifikasi.

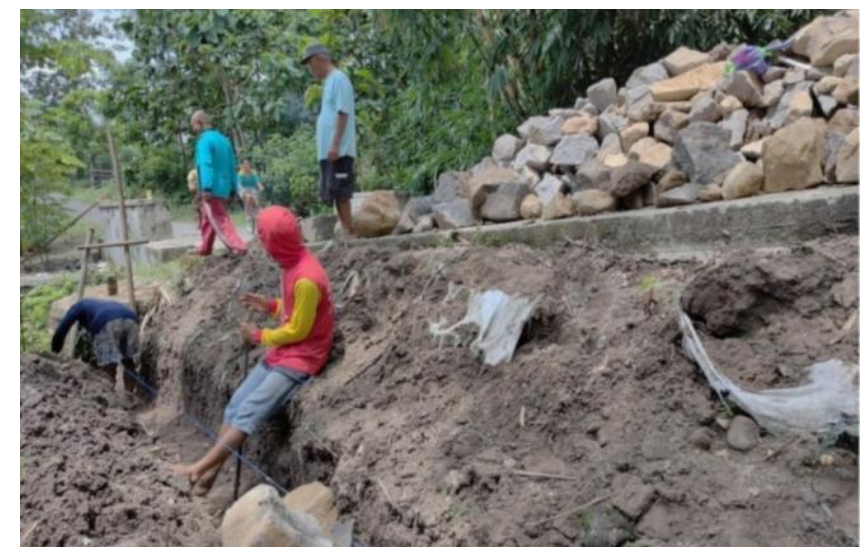

Gambar 1. Pekerjaan Talud di Desa Tladan

\section{METODE PELAKSANAAN}

Metode kegiatan yang dilakukan dalam kegiatan pengabdian ini adalah memberikan sosialisasi pada masyarakat di Desa Tladan Kecamatan Kawedanan Kabupaten Magetan. Sosialisasi berupa ceramah dengan menyampaikan materi terkait penyusunan RAB talud. Untuk memudahkan penyampaian materi, menggunakan LCD proyektor sehingga lebih mudah dipahami. Setelah penyampaian materi, diberikan pelatihan penyusunan RAB dengan menggunakan program MS Excel 2013. Dengan pelatihan tersebut, peserta diajak langsung menerapkan pengetahuan cara menyusun RAB talud dengan mengambil obyek pada salah satu lokasi yang rencananya akan direalisasikan pada tahun depan. Untuk mengetahui tingkat keberhasilan pelatihan, dilakukan pre-test dan post-test terhadap peserta pelatihan. Pre-test dilakukan sebelum pelatihan, sedangkan post-test dilakukan setelah pelatihan berakhir. 
Website : http://dayamas.unmermadiun.ac.id/index.php/dayamas

\section{HASIL DAN PEMBAHASAN}

Pelatihan dilaksanakan selama 4 minggu dengan jumlah pertemuan 3 kali perminggu. Lokasi pelatihan di kantor Kepala Desa Tladan yang terletak di Jalan Raya Gorang Gareng Lembeyan Kecamatan Kawedanan Kabupaten Magetan. Peserta pelatihan terdiri dari Perangkat Desa, perwakilan karang taruna dan warga yang berminat serta biasa membantu dalam program infrastruktur desa.

RAB berfungsi untuk menghitung biaya kebutuhan proyek kontruksi mulai dari bahan, upah tenaga kerja, dan peralatan yang digunakan. RAB mempermudah owner untuk memprediksi jumlah anggaran yang dibutuhkan dalam pembangunan. RAB juga digunakan sebagai pedoman dalam melaksanakan suatu pekerjaan dan pengontrol pelaksanaan pekerjaan.

Ketelitian dan bekal ilmu yang baik sangat diperlukan untuk membuat RAB proyek kontruksi. Selain itu kemahiran dalam mengoperasikan alat bantu komputer untuk membuat RAB mutlak diperlukan agar mempercepat proses pembuatan RAB.

Untuk meningkatkan kemampuan tim pembangunan pedesaan khususnya Desa Tladan, maka perlu dilakukan pelatihan pembuatan $\mathrm{RAB}$, khususnya pekerjaan dinding penahan tanah. Dengan pelatihan tersebut diharapkan dapat membantu kesulitan-kesulitan yang dihadapi dan memberikan solusi terbaik atas kendala-kendala tesebut.

Hal-hal yang perlu diperhatikan dalam perhitungan RAB pedesaan :

1. RAB yang disusun oleh masyarakat, harus dilakukan oleh orang yang mampu dan memahami cara pembuatan RAB.

2. RAB harus disusun secara teliti, hati-hati, dan benar sehingga diperoleh nilai RAB yang seimbang dengan biaya pelaksanaan kegiatan sarana prasarana yang telah direncanakan (RAB realistis) atau dengan kata lain bahwa RAB yang disusun tidak berlebihan (pemborosan) atau kekurangan dana (kualitas atau kuantitas pekerjaan tidak dapat dipenuhi).

3. RAB bersifat terbuka, artinya siapapun warga masyarakat dengan mudah mengakses dan mengetahuinya.

4. Apabila terjadi kekurangan dana pada tahap pelaksanaan sarana prasarana, maka harus diupayakan melalui swadaya agar memenuhi kualitas dan kuantitas pekerjaan sesuai yang direncanakan.

5. Sebaliknya, jika terdapat kelebihan dana, maka harus digunakan kembali hanya pada paket kegiatan yang bersangkutan dengan cara menambah volume atau menyempurnakan sarana prasarana yang dibangun.

Adapun tahapan dalam melakukan pembuatan RAB adalah sebagai berikut :

1. Survey lapangan

Survey lapangan bertujuan untuk mengetahui area yang akan dibangun dan melakukan pengukuran lokasi tempat pembangunan yang nantinya akan dituangkan dalam gambar rencana. Dari hasil survey dapat diperoleh tinggi talud yang akan direncanakan beserta ukuran-ukurannya dan layout situasi di sekitar talud.

2. Membuat detail gambar rencana

Gambar rencana berfungsi untuk mengetahui ukuran dan bentuk dari bangunan yang akan dibangun guna menghitung besarnya volume setiap item pekerjaan. Detail rencana disesuaikan dengan kondisi medan dan permohonan owner dengan mempertimbangkan pagu anggaran yang tersedia 
Website : http://dayamas.unmermadiun.ac.id/index.php/dayamas

3. Perhitungan volume

Perhitungan volume talud didasarkan gambar rencana yang telah dibuat. Cara perhitungan volume dinding penahan tanah adalah dengan mencari luas penampang talud, kemudian dikalikan panjang talud yang direncanakan.

4. Setelah volume dihitung, langkah selanjutnya melakukan survey harga satuan baik bahan, upah maupun peralatan yang akan digunakan. Survey dilakukan pada toko bahan bangunan di sekitar lokasi

5. Menghitung harga satuan pekerjaan talud

Untuk pekerjaan tanah mengacu pada SNI 2835 : 2008 tentang Tata Cara Perhitungan Harga Satuan Pekerjaan Tanah Untuk Konstruksi Bangunan Gedung Dan Perumahan Harga satuan pekerjaan badan talud disusun dengan mengacu pada SNI 2836: 2008 tentang Tata Cara Perhitungan Harga Satuan Pekerjaan Pondasi Untuk Konstruksi Bangunan Gedung dan Perumahan

Untuk pekerjaan plesteran mengacu pada SNI 2837: 2008 tentang Tata Cara Perhitungan Harga Satuan Pekerjaan Plesteran Untuk Konstruksi Bangunan Gedung dan Perumahan.

6. Melakukan perhitungan volume pekerjaan bangunan pelengkap talud

7. Menghitung biaya yang dibutuhkan dengan mengalikan antara volume dengan harga satuan

8. Membuat schedule pelaksanaan

9. Menetapkan spesifikasi teknis yang akan digunakan disesuaikan dengan RAB.

Contoh langkah dalam melakkukan perhitungan RAB pembuatan dinding penahan tanah adalah sebagai berikut :

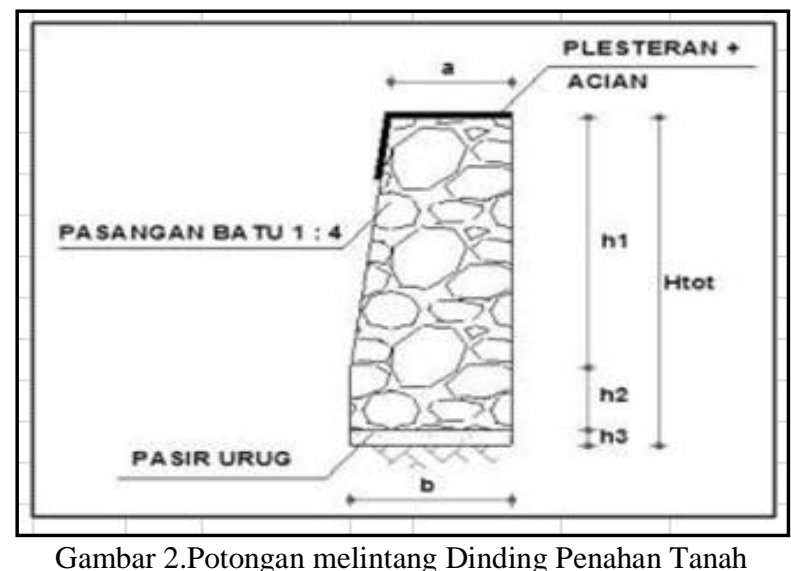

Dari hasil pengukuran lapangan, diketahui rencana panjang talud adalah 30 meter $(\mathrm{L}=30 \mathrm{~m}), \mathrm{a}=30 \mathrm{~cm}, \mathrm{~b}=60 \mathrm{~cm}, \mathrm{~h}_{1}=2 \mathrm{~m}, \mathrm{~h}_{2}=60 \mathrm{~cm}, \mathrm{~h}_{3}=5 \mathrm{~cm}$, dan $\mathrm{h}_{\text {Tot }}=265 \mathrm{~cm}$. Selanjutnya menghitung volume semua material yang dibutuhkan. Perhitungan volume dapat dijelaskan sebagai berikut :

a. Menghitung volume galian

$\mathrm{V}$ galian $=0,6 \times 0,65 \times 30$

$$
=11,70 \mathrm{~m}^{3}
$$

b. Menghitung volume urugan

V urugan $=0,6 \times 0,05 \times 30$

$$
=0,9 \mathrm{~m}^{3}
$$


Website : http://dayamas.unmermadiun.ac.id/index.php/dayamas

c. Menghitung volume pasangan batu belah

$$
\begin{aligned}
\text { V kaki } & =0,6 \times 0,6 \times 30 \\
& =10,80 \mathrm{~m}^{3} \\
\mathrm{~V} \text { dinding } & =0,45 \times 2 \times 30 \\
& =27 \mathrm{~m}^{3}
\end{aligned}
$$

d. Menghitung volume plesteran

$\mathrm{V}$ plesteran $=0,4 \times 30=12 \mathrm{~m}^{2}$

Adapun langkah selanjutnya adalah menghitung jumlah biaya. Jumlah biaya didapat

\begin{tabular}{|c|c|c|c|c|}
\hline No. & Uraian & Volume & $\begin{array}{l}\text { Harga } \\
\text { Satuan }\end{array}$ & Jumlah \\
\hline $\mathbf{I}$ & BAHAN & & & \\
\hline 1 & Batu belah & $45 \mathrm{~m}^{3}$ & 150.000 & 5.700 .000 \\
\hline 2 & Semen @40kg & $112 \mathrm{zak}$ & 45.000 & 5.040 .000 \\
\hline 3 & Pasir pasang & $21 \mathrm{~m}^{3}$ & 250.000 & 5.250 .000 \\
\hline 4 & Tanah urug & $5 \mathrm{~m}^{3}$ & 75.000 & 375.000 \\
\hline 5 & Kayu profil 3/4 & 67 lonjor & 5.000 & 335.000 \\
\hline 6 & Paku & $0,36 \mathrm{~kg}$ & 14.000 & 5.040 \\
\hline 7 & Paralon 3/4" & $4 \mathrm{bh}$ & 20.000 & 80.000 \\
\hline \multirow[t]{2}{*}{8} & Ijuk & $4 \mathrm{~kg}$ & 5.000 & 20.000 \\
\hline & & & & 17.855 .040 \\
\hline II & ALAT & & & \\
\hline 1 & Benang & $3 \mathrm{rol}$ & 5.000 & 15.000 \\
\hline 2 & Ember & $5 \mathrm{bh}$ & 10.000 & 50.000 \\
\hline 3 & Kuas & $6 \mathrm{bh}$ & 5.000 & 30.000 \\
\hline 4 & Sewa molen & 4 hari & 75.000 & 300.000 \\
\hline 5 & Tong air & $1 \mathrm{bh}$ & 90.000 & 90.000 \\
\hline 6 & Kawat ayakan & $2 \mathrm{~m}$ & 20.000 & 40.000 \\
\hline 7 & Selang timbangan & $30 \mathrm{~m}$ & 2.000 & 60.000 \\
\hline \multirow[t]{2}{*}{8} & Sekop & $3 \mathrm{bh}$ & 40.000 & 120.000 \\
\hline & & & & 705000 \\
\hline III & UPAH & & & \\
\hline 1 & Pekerja & $70 \mathrm{OH}$ & 80.000 & 5.600 .000 \\
\hline 2 & Tukang batu & $31 \mathrm{OH}$ & 90.000 & 2.790 .000 \\
\hline 3 & Kepala tukang & $4 \mathrm{OH}$ & 100.000 & 400.000 \\
\hline \multirow[t]{7}{*}{4} & Mandor & $2 \mathrm{OH}$ & 110.000 & 330.000 \\
\hline & & & & 9.120 .000 \\
\hline & \multicolumn{2}{|l|}{ Total } & & 27.680 .040 \\
\hline & \multicolumn{2}{|l|}{ Operasional (5\%) } & & 1.384 .002 \\
\hline & \multicolumn{2}{|l|}{ PPH $(15 \%)$} & & 4.152 .006 \\
\hline & \multicolumn{2}{|l|}{ PPN $(10 \%)$} & & 2.768 .004 \\
\hline & \multicolumn{2}{|l|}{ Jumlah Total Biaya } & & 35.984 .052 \\
\hline
\end{tabular}
dari hasil perkalian volume dengan harga satuan. Untuk perhitungan RAB keseluruhan disajikan dalam tabel 1 berikut :

Tabel 1. Rencana Anggaran Biaya Pembangunan Talud

Materi disampaikan kepada peserta dengan menggunakan MS Power point dan ditampilkan pada LCD proyektor. Materi meliputi dasar pengetahuan talud, langkah penyusunan $\mathrm{RAB}$ talud, perhitungan volume, perhitungan harga satuan dan penyusunan RAB keseluruhan. Setelah penyampaian materi diberikan latihan berupa tugas menyusun RAB talud dengan dipandu sampai selesai. Hasil pelatihan peserta dapat dilihat pada gambar 4 tentang analisis harga satuan dan gambar 5 tentang rekapitulasi RAB. 
Website : http://dayamas.unmermadiun.ac.id/index.php/dayamas

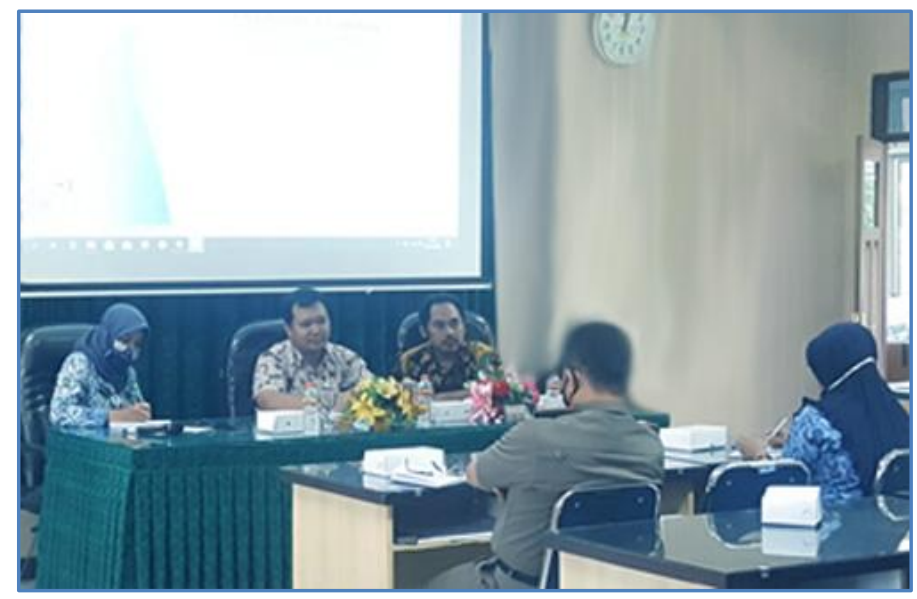

Gambar 3. Penyampain Materi

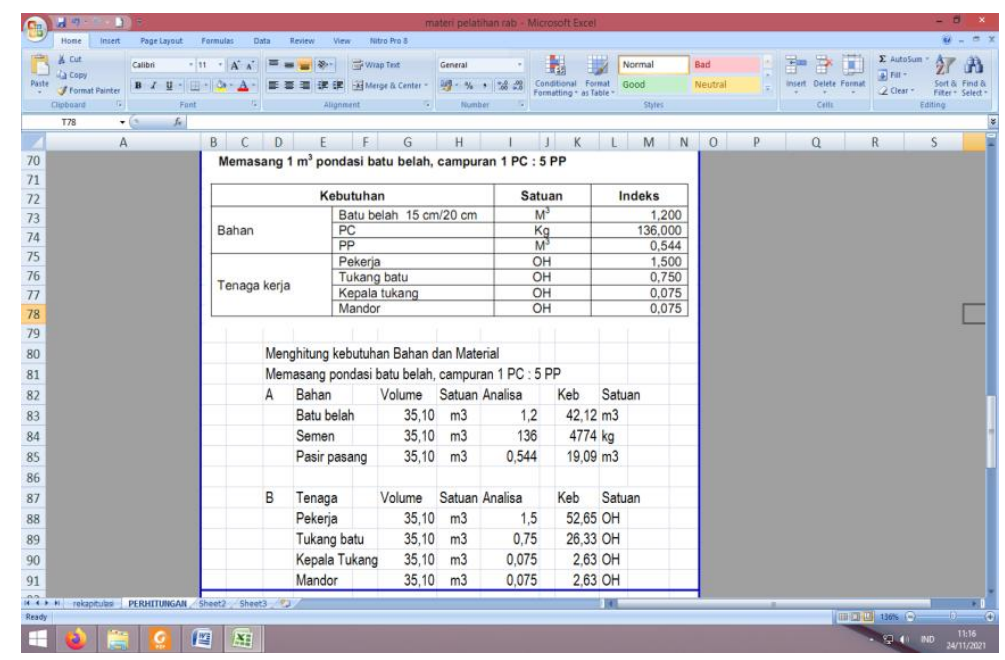

Gambar 4. Analisis harga satuan

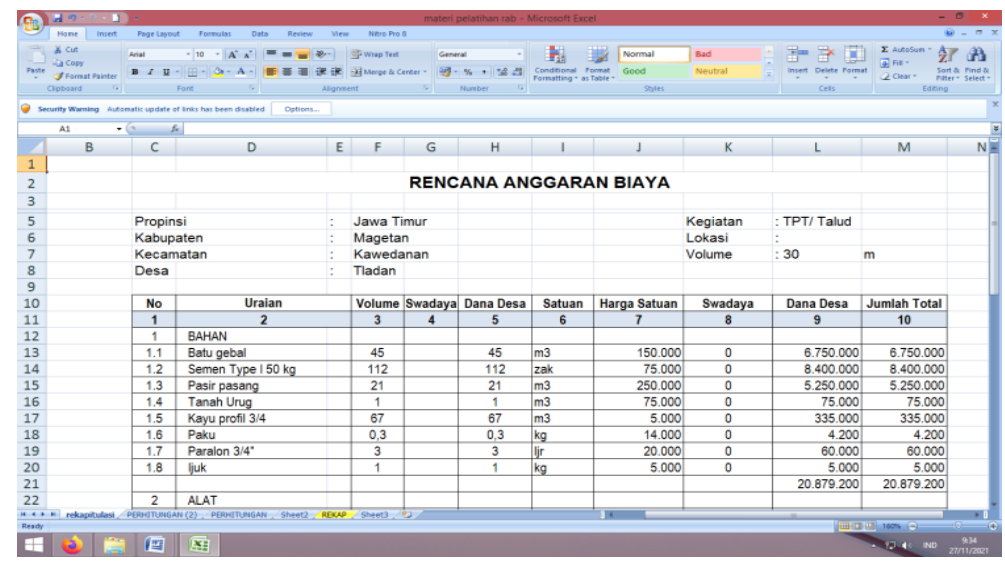

Gambar 5. Rekapitulasi RAB

Volume 6 Nomor 2 September 2021, DAYA - MAS $\mid 92$ 
Website : http://dayamas.unmermadiun.ac.id/index.php/dayamas

Setelah diadakan penyampaian materi dan pelatihan terhadap 15 orang peserta yang mengikuti dapat diketahui beberapa hal sebagai berikut :

1. Semua peserta belum pernah menggunakan aplikasi MS Excel pada pembuatan RAB talud. Selama ini penyusunan RAB masih menggunakan metode manual sehingga memerlukan waktu yang lebih lama.

2. Semua peserta belum mengetahui analisis harga satuan sesuai SNI harga satuan pekerjaan. Selama ini hanya menggunakan perkiraan. Setelah disampaikan SNI harga satuan mereka dapat memahami cara menghitung kebutuhan material sesuai spesifikasi yang ditentukan.

3. Peserta yang dapat mengikuti pelatihan sampai selesai terdapat 12 orang (dari total peserta di awal pertemuan 15 orang). Respons mereka terhadap kegiatan sangat antusias. Peserta aktif mencoba aplikasi MS Excel dengan menggunakan laptop dan aktif bertanya selama pelatihan.

4. Setelah pelatihan berakhir, peserta dapat menyelesaikan materi pelatihan dan dapat menghitung sendiri RAB yang dibutuhkan untuk membuat talud sepanjang $30 \mathrm{~m}$.

5. Pada akhir pelatihan peserta dipersilakan menyampaikan saran dan masukan terkait pelatihan. Peserta menyampaikan saran agar pelatihan terkait RAB dilaksanakan pada waktu yang akan datang.

Pelatihan penyusunan RAB talud ini diharapkan dapat meningkatkan kemampuan masyarakat dalam meningkatkan kualitas perencanaan pembangunan di desa, agar pada waktu pelaksanaan lebih lancar dan dapat mengaplikasikan ilmu yang telah disampaikan. Untuk tahap awal diperlukan pendampingan, sehingga dapat mempercepat proses transfer pengetahuan di masyarakat, khususnya berkaitan penyusunan RAB.

Untuk mengetahui capaian keberhasilan pelatihan maka dilakukan pre-test dan post-test terhadap peserta yang mengikuti. Hasil pre-test dan post-test disajikan pada gambar berikut.

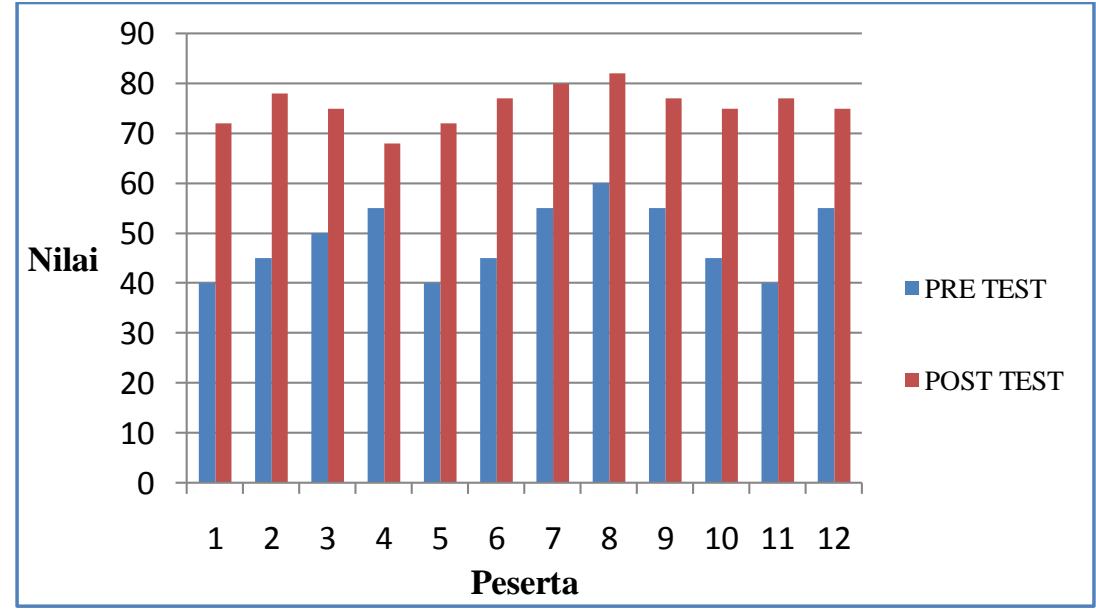

Gambar 6. Hasil penilaian terhadap peserta

Dari gambar 6 dapat dilihat bahwa semua peserta mengalami kenaikan nilai post-tes dibandingkan nilai pre-test. Hal ini menunjukkan bahwa pengetahuan peserta terhadap materi RAB talud mengalami peningkatan. Nilai post-test tertinggi adalah peserta nomor 8 atas nama Saudara Riyanto, sedangkan nilai terendah peserta nomor 4. Secara umum dapat dikatakan bahwa peserta dapat menyerap materi yang disampaikan dengan baik dan dapat mengaplikasikan pengetahuan tersebut dengan menggunakan program bantu MS Excel 2013. 
Website : http://dayamas.unmermadiun.ac.id/index.php/dayamas

\section{PENUTUP} berikut :

Setelah pelaksanaan pelatihan penyusunan RAB talud dapat disimpulkan sebagai

1. Pelatihan penyusunan RAB talud dapat meningkatkan kemampuan peserta sehingga dapat menyusun RAB lebih cepat daripada yang dilakukan selama ini.

2. Semua peserta yang mengikuti pelatihan sampai selesai dapat menerapkan materi yang diberikan.

3. Kendala yang dihadapi dalam pelatihan adalah tidak semua peserta memiliki kemampuan dasar MS Excel sehingga sebagian membutuhkan waktu lebih lama untuk menyerap materi.

\section{UCAPAN TERIMAKASIH}

Kami mengucapkan terimakasih kepada Bapak Ketua Yayasan Perguruan Tinggi Merdeka Madiun, Bapak Rektor Universitas Merdeka Madiun, Bapak Ketua LPPM Universitas Merdeka Madiun, Bapak Dekan Fakultas Teknik Universitas Merdeka Madiun, Bapak Kepala Desa Tladan beserta perangkat dan semua pihak yang telah membantu dalam pelaksanaan pelatihan ini sehingga dapat terlaksana dengan baik. 
Website : http://dayamas.unmermadiun.ac.id/index.php/dayamas

\section{DAFTAR PUSTAKA}

Anonim, 2008, SNI 2835 : 2008, SNI Tata Cara Perhitungan Harga Satuan Pekerjaan Tanah Untuk Konstruksi Bangunan Gedung Dan Perumahan.

Anonim, 2008, SNI 2836: 2008, Tata Cara Perhitungan Harga Satuan Pekerjaan Pondasi Untuk Konstruksi Bangunan Gedung Dan Perumahan.

Anonim, 2008, SNI 2837: 2008, Tata cara perhitungan harga satuan pekerjaan plesteran untuk konstruksi bangunan gedung dan perumahan.

Anonim, 2008, SNI 6897: 2008, Tata cara perhitungan harga satuan pekerjaan dinding untuk konstruksi bangunan gedung dan perumahan.

Anonim, 2008, SNI 7394: 2008, Tata cara perhitungan harga satuan pekerjaan beton untuk konstruksi bangunan gedung dan perumahan.

Budi Santoso, 2003, Manajemen Proyek, ITS Surabaya.

Hardiyatmo, H.C. 2010, Analisis dan Perencanaan Fondasi bagian I, Gajah Mada University Press, Yogyakarta.

Wulfram I. Ervianto, 2015, Manajemen Proyek Kontruksi, ANDI Yogyakarta. 